\title{
Modelling of a Spark Ignition Engine for Power-Heat Production Optimization
}

\author{
D. Descieux and M. Feidt \\ LEMTA UMR 7563, CNRS-INPL-UHP, Laboratoire d'Energétique et de Mécanique Théorique et Appliquée, 2 avenue de la Forêt de Haye, \\ BP 160, 54516 Vandœuvre-lès-Nancy - France \\ e-mail: damien-descieux@lermab.uhp-nancy.fr - michel.feidt@ensem.inpl-nancy.fr
}

\begin{abstract}
Résumé - Modèle de moteur à allumage commandé en vue de l'optimisation de la production chaleur-force - Le moteur à allumage commandé alimenté en gaz est un moteur de plus en plus utilisé pour la production simultanée d'électricité et de chaleur. Classiquement le moteur entraîne sur l'arbre une génératrice électrique. Le flux thermique est récupéré principalement sur le système de refroidissement du moteur ainsi que sur les fumées chaudes et il est généralement utilisé pour produire de la chaleur pour les systèmes de chauffage. Pour avoir une meilleure adaptation entre la production du moteur et la demande de l'usager, une bonne connaissance des évolutions dans le moteur et des phénomènes correspondants est nécessaire. Une méthode thermodynamique générale est proposée pour simulation du fonctionnement dynamique stationnaire d'un MACI. Le modèle utilise une analyse monozone et les caractéristiques de chaque transformation du cycle pour étudier les performances énergétiques : rendement exergétique de l'ordre de 0,70 .
\end{abstract}

\begin{abstract}
Modelling of a Spark Ignition Engine for Power-Heat Production Optimization - Spark ignition gas engine is more and more used in order to produce electricity and heat simultaneously. The engine crankshaft drives a synchronous electric generator. The thermal power output is recovered from the engine coolant system and exhaust gas, and is used to produce generally hot water for heating system. In order to have a better adequacy between supply (production of the engine) and user demand, good knowledge of the engine and implemented phenomena are necessary. A generic methodology is proposed to simulate the stationary state response of a SI engine. The engine simulation is based on a one zone thermodynamic model, which characterizes each phase of the engine cycle to predict energy performances: exergy efficiency as high as 0.70 is attainable.
\end{abstract}




\section{NOMENCLATURE}

\section{Roman characters}

$\begin{array}{ll}A & \text { Area }\left(\mathrm{m}^{2}\right) \\ B & \text { Bore }(\mathrm{m}) \\ C_{d} & \text { Discharge coefficient } \\ c_{p} & \text { Specific heat at constant pressure }(\mathrm{J} / \mathrm{kg} . \mathrm{K}) \\ E V C & \text { Exhaust Value Closing } \\ E V O & \text { Exhaust Value Opening } \\ L H V & \text { Lower Heating Value }(\mathrm{kJ} / \mathrm{kg}) \\ h & \text { Heat exchange coefficient }\left(\mathrm{W} / \mathrm{m}^{2} \cdot \mathrm{K}\right) \\ L & \text { Rod length }(\mathrm{m}) \\ N & \text { Revolution per minute }(\mathrm{tr} / \mathrm{min}) \text { or }(\mathrm{rpm}) \\ P & \text { Pressure }(\text { Pa) } \\ Q & \text { Heat }(\mathrm{J}) \\ r & \text { Ideal gas constant } \\ S & \text { Entropy }(\mathrm{J} / \mathrm{kg} . \mathrm{K}) \\ S t & \text { Stroke }(\mathrm{m}) \\ S_{x} & \text { Area }\left(\mathrm{m}^{2}\right) \\ T & \text { Temperature }(\mathrm{K}) \\ T D C & \text { Top Dead Center } \\ B D C & \text { Bottom Dead Center } \\ V & \text { Volume }\left(\mathrm{m}^{3}\right) \\ v & \text { Speed }(\mathrm{m} / \mathrm{s}) \\ X & \text { Current position }(\mathrm{m})\end{array}$

\section{Greek characters}

$\gamma \quad$ Specific heat ratio

$\varepsilon \quad$ Compression ratio

$\theta \quad$ Crankshaft angle (deg)

$\theta_{0} \quad$ Outbreak combustion angle (deg)

$\Delta \theta_{d} \quad$ Combustion duration (deg)

$\phi \quad$ Fuel air equivalence ratio

$\omega \quad$ Rotation speed ( $\mathrm{rad} / \mathrm{s})$

\section{Subscripts}

$\begin{array}{ll}\text { atm } & \text { Atmosphere } \\ \text { clear } & \text { Clearance volume } \\ d & \text { Combustion duration } \\ \text { exh } & \text { Exhaust } \\ \text { in } & \text { Intake } \\ \text { rec } & \text { Recovered } \\ \text { pis } & \text { Piston } \\ \text { comb } & \text { Combustion } \\ g & \text { Gas } \\ p & \text { Pressure }\end{array}$

$\begin{array}{ll}v & \text { Valve } \\ \text { stoech } & \text { Stoechiometric } \\ f & \text { Fuel } \\ w & \text { Wall } \\ g w & \text { Gas wall } \\ \text { upst } & \text { Upstream } \\ \text { downst } & \text { Downstream }\end{array}$

\section{INTRODUCTION}

Several authors have applied the so called finite-time thermodynamics to the analysis and optimization of the internalcombustion engine. Some models are relative to general approach [1] defining a class of irreversible reciprocating heat engines. Hoffman et al. [2] used mathematical techniques as optimal-control theory to determine the optimal motion of the piston in Otto and Diesel engines. AnguloBrown et al. [3] and later other authors [4, 5, 7] focus on Otto engines. Angulo-Brown considers the compression ratio associated to optimized power. Ebrahimi reports on the effect on variable specific heat ratio for an endoreversible Otto engine. Diesel engine has been considered too by Chen et al. [6] and Ebrahimi [7]. The Chen's paper analyzes the Diesel engine performance in presence of friction effect. Ebrahimi focuses on the influence of the stroke length and compression ratio for the same engine. The irreversible cycle was also considered by Chen et al. [8], Ghatak and Chakraborty [9], and Ge et al. [10]. Ghatak and Chakraborty considered the influence of external irreversibilities and variable thermal properties on the performance of dual cycle engine. Chen et al. derives the relation between net power output and efficiency.

Finally, Angulo-Brown et al. [11] and Rocha-Martinez et al. [12] take account of the combustion reaction and consequences. But there are thermal losses as noted by Chen et al. [13]. In fact, these authors suppose that thermal losses occur only for the transformations with contact at the source (combustion) and sink (ambiance), but not during isentropic transformations. Each heat transfer law is supposed such that $d T / d t=$ constant, but different at the source and sink. Merabet et al. [14] proposed a model for which the thermal loss is represented more classical, in the form of a thermal conductance between the arithmetic mean temperature of gases, on each transformation $V=$ constant, $P=$ constant, compared to the wall temperature $T_{w}$. Here, we take account of the non-adiabaticity over the cycle duration as Hoffmann did, but with another correlation for the exchange coefficient.

The results are presented in traditional form according to the number of revolutions, but also in more integrated and compact form, and more complete than was done originally by Chen et al. [6]: the corresponding curve represents the engine power versus the efficiency. 
The presented results are representative of a tested gas engine.

In this paper we also propose to treat the problem of maximizing the value of the rejected heat together with the mechanical power of the engine. In order to achieve this goal an exergy appraisal is proposed by considering the exergy consumption related to combustion, mechanical power that is pure exergy, and rejected exergy associated to the heat in flue gas, and water cooling system: an exergy efficiency of the system is deduced.

Section 1 reports on the model, while Section 2 on some results and corresponding discussion.

\section{SPARK IGNITION ENGINE MODELLING}

This paper intends to develop a model for stationary engine applications, and particularly Combined Heat and Power engine. For the CHP Spark Ignition engine a "one zone" model is used hereafter, i.e. the state of the cylinder charge is defined in terms of average spatial properties. Pressure, temperature and composition of cylinder charge are assumed to be uniform in the cylinder at each time step that is to say that no separation is made between burned and unburned gas during the combustion phase inside the cylinder, see Figure 1.

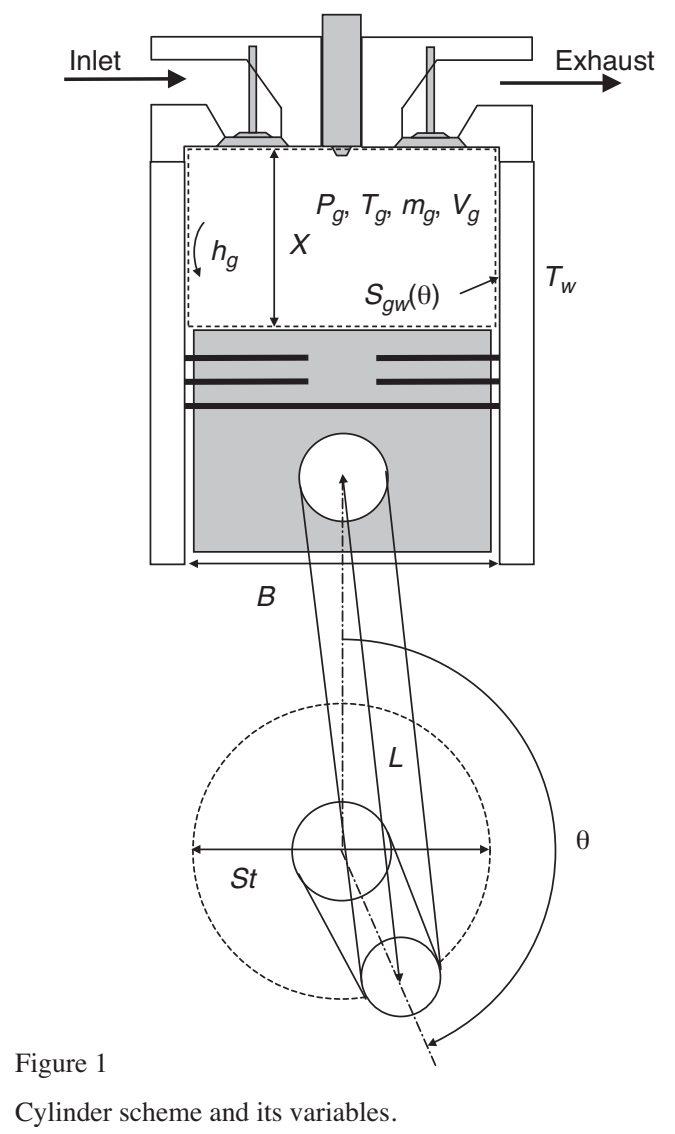

If $r_{b m}=\frac{2 \cdot L}{S t}$ then the instantaneous cylinder volume $V_{g}(\theta)$ depends on the piston position $X(\theta)$ and is calculated by the following equation:

$$
\begin{aligned}
& V_{g}(\theta)=V_{\text {clear }}+\frac{\pi \cdot B^{2}}{4} \cdot L \cdot \\
& \left(1+r_{b m}-\sqrt{1-r_{b m}{ }^{2} \cdot \sin (\theta)^{2}}-r_{b m} \cdot \cos (\theta)\right)
\end{aligned}
$$

where $V_{\text {clear }}=\frac{V_{g}(\pi)}{\varepsilon}$ with $\varepsilon$ the compression ratio.

The volume $V_{g}(\theta)$, occupied by gas is regarded as the geometrical variable.

Being given the three state variables, three equations are necessary to determine the evolution of these state variables in the combustion chamber.

\subsection{General Equation of the Model}

\subsubsection{Mass Conservation}

The conservation equation of the mass applied to the control volume is written:

$$
\frac{d m_{g}(\theta)}{d \theta}=\frac{d m_{i n}(\theta)}{d \theta}+\frac{d m_{e x h}(\theta)}{d \theta}
$$

\subsubsection{Perfect Gas}

The model of perfect gas provides an equation of connection between the mass present in the control volume $m_{g}(\theta)$, its volume $V_{g}(\theta)$, its pressure $P_{g}(\theta)$, and its temperature:

$$
\frac{d T_{g}(\theta)}{d \theta}=T_{g}(\theta) \cdot\left[\begin{array}{c}
\frac{1}{P_{g}(\theta)} \frac{d P_{g}(\theta)}{d \theta} \\
+\frac{1}{V_{g}(\theta)} \frac{d V_{g}(\theta)}{d \theta} \\
-\frac{1}{m_{g}(\theta)} \frac{d m_{g}(\theta)}{d \theta}
\end{array}\right]
$$

The assumption of perfect gas is also employed in the formulation of the heat exchange coefficient, between gas-wall, according to [15]. Indeed, the calculation of the Reynolds number of combustion gases requires to know their density which is evaluated starting from this model of perfect gas.

\subsubsection{Entropy Balance}

The entropy $S$ corresponding to the mass $m_{g}$ of gas, encapsulated in the cylinder:

$$
\frac{d S_{g}(\theta)}{d \theta}=m_{g}(\theta) \cdot c_{p} \frac{d T_{g}}{T_{g} \cdot d \theta}-m_{g}(\theta) \cdot r \cdot \frac{d P_{g}}{P_{g} \cdot d \theta}
$$

Combining Equations (4) and (3) leads after some calculation to Equation (5).

Then the entropy is expressed as a ratio between heat and a reference temperature, $T_{g}$. 
The gas contained in the control volume exchanges a quantity of enthalpy at the admission and another one at the time of the exhaust $d H$ (this term will be precized in Sect. 1.2). Moreover the gas furnishes heat to the wall (thermoconvective and radiative exchange) $Q_{g w}$ and receives some thanks to combustion $Q_{\text {comb }}$ according to:

$$
\begin{aligned}
& \frac{d P_{g}(\theta)}{d \theta}=\gamma \cdot P_{g}(\theta) \cdot\left(\frac{d m_{g}(\theta)}{m_{g}(\theta) \cdot d \theta}-\frac{d V_{g}(\theta)}{V_{g}(\theta) \cdot d \theta}\right) \\
& +\frac{\gamma-1}{V_{g}(\theta)} \cdot\left(\frac{d H(\theta)}{d \theta}+\frac{d Q_{g w}(\theta)}{d \theta}+\frac{d Q_{\text {comb }}(\theta)}{d \theta}\right)
\end{aligned}
$$

$\gamma$, the specific heat ratio, is not that of perfect gas but a corrected coefficient equal to 1.3 for all the duration of the cycle, see Reference [16]. A further step of the model could be to take account of the temperature dependence of this specific heat ratio like in [5].

\subsection{Details of the Model: Transfer and Combustion}

\subsubsection{Mass Flow Rate Equation}

The real flows in the pipes of admission and exhaust are complex pulsated flows. To simplify calculations [17], the gas flow on the valves is assimilated to a throttling process comparable with that occurring in a nozzle.

The throughput speed of gas is then obtained with the conditions upstream and downstream from the nozzle. The mass flow rate is obtained with geometrical data:

$$
\begin{aligned}
& \frac{d m_{g}(\theta)}{d \theta}=\delta_{v} \cdot \frac{C d \cdot A_{v} \cdot P_{u p s t}}{\omega} \cdot \\
& \sqrt{\left(\frac{2 \cdot \gamma}{(\gamma-1) \cdot r \cdot T_{u p s t}}\right) \cdot\left(R_{p}^{2 \cdot \gamma-1}-R_{p}^{\frac{\gamma-1}{\gamma}}\right)}
\end{aligned}
$$

The $A_{v}$ term represents the geometrical valve flow area and depends on valve lift, $C d$ represents the coefficient of discharge of the valve, $\delta_{v}$ takes the value 1 during intake, -1 during exhaust and 0 during the other phases. The pressure ratio $R_{p}$ is limited by the sonic conditions collar through the passage of the valve: the flow is maximum when the speed of the fluid at the collar reaches the speed of sound. The pressure ratio $R_{p}$ is written as follows:

$$
R_{p}^{\lim }=\left(\frac{2}{\gamma-1}\right)^{\frac{\gamma}{\gamma-1}}
$$

Then the pressure ratio:

$$
R_{p}= \begin{cases}\frac{P_{\text {downst }}}{P_{\text {upst }}} & \text { if } \quad \frac{P_{\text {downst }}}{P_{\text {upst }}} \geq R_{p}^{\mathrm{lim}} \\ R_{p}^{\lim } & \text { if } \quad \frac{P_{\text {downst }}}{P_{\text {upst }}}<R_{p}^{\lim }\end{cases}
$$

Valve lift of the valve $l_{v, i}$, depends on crankshaft angle:

$$
l_{v, i}=\frac{L_{v \max , i}}{2}\left(1+\sin \left(\frac{2 \pi}{\Delta \theta_{i}}\left(\theta_{i}^{*}-\frac{\Delta \theta_{i}}{2}\right)+\frac{\pi}{2}\right)\right)
$$

$\theta_{i}^{*}$ is a translation of the crankshaft angle $\theta$, a parameter for the value of the valve $i$ opening. $\Delta \theta_{i}$ is the opening duration of the valve $i$.

\subsubsection{Enthalpy Variation}

The enthalpy variation, $d H$, of combustion gases during a transformation $d \theta$ is the sum of the variation of enthalpy brought by fresh gases at the admission and the carrying out of this one with exhaust gases.

For this term as for heat release on the flue gas the specific heat at constant pressure is described by a polynomial model function of the exhaust gas temperature $T_{g}$ given in Reference [18].

$$
\begin{aligned}
& c_{p}\left(T_{g}\right)=1403.06-360 \cdot x+108 \cdot x^{2}-10.79 \cdot x^{3} \\
& \text { with } x=\frac{1000}{T_{g}}
\end{aligned}
$$

\subsubsection{Heat Exchange Correlation}

Heat exchanges at cylinder walls are represented by the Woschni correlation modified by Hohenberg [15]:

$$
h_{g}(\theta)=k_{\text {hoh }} \cdot \frac{\left(10^{-5} \cdot P_{g}(\theta)\right)^{0.8} \cdot\left(\overline{v_{p i s}}+1.4\right)^{0.8}}{T_{g}(\theta)^{0.4} \cdot V_{g}(\theta)^{0.06}}
$$

with $k_{\text {hoh }}$, constant of Hohenberg correlation.

The heat loss by thermo convective and radiative heat exchanges results as:

$$
\frac{d Q_{g w}(\theta)}{d \theta}=\frac{h_{g}(\theta) \cdot S_{g w}(\theta) \cdot\left(T_{w}-T_{g}(\theta)\right)}{\omega}
$$

where $T_{w}$ is the wall temperature supposed constant.

\subsubsection{Combustion Model}

The heat release is modeled using a simple Wiebe law, which describes the combustion process:

$$
\frac{d Q_{\text {comb }}}{d \theta}=m_{f} \cdot L H V \cdot \frac{d \chi(\theta)}{d \theta}
$$

where $L H V$ denotes Lower Heating Value of the fuel: $\frac{d \chi(\theta)}{d \theta}$ the combustion rate obtained by the Wiebe function is valid for $\theta_{0} \geq \theta \geq \theta_{0}+\Delta \theta_{d}$ and null elsewhere according to:

$$
\frac{d \chi(\theta)}{d \theta}=\frac{a \cdot(b+1)}{\Delta \theta_{d}}\left(\frac{\theta-\theta_{0}}{\Delta \theta_{d}}\right)^{b} \exp \left[-a \cdot\left(\frac{\theta-\theta_{0}}{\Delta \theta_{d}}\right)^{b+1}\right]
$$

$\theta_{0}$ is the crankshaft angle marking the outbreak of the combustion and $\Delta \theta_{d}$ is the combustion duration. 
Arquès [19] proposed an expression for SI engine of the form factor $b$ and of the combustion duration $\Delta \theta_{d}$ :

$$
\begin{gathered}
b=1.3 \cdot \frac{\varepsilon^{0.166} \cdot\left(\frac{N}{1000}\right)^{0.465}}{\phi^{0.121} \cdot B^{0.126} \cdot S t^{0.205}} \\
\Delta \theta_{d}=2.3 \cdot \frac{B^{0.03} \cdot \varepsilon^{0.266} \cdot\left(\frac{N}{1000}\right)^{1.12}}{\phi^{0.547} \cdot S t^{1.37}}
\end{gathered}
$$

$m_{f}$ the mass of injected fuel inside the cylinder is directly connected to the fuel/air equivalence ratio through $\Phi$ :

$$
\phi^{-1}=\frac{(A / F)_{\text {actual }}}{(A / F)_{\text {stoech }}}, \text { then } m_{f}=\frac{\phi \cdot m_{g}}{(A / F)_{\text {stoech }}}
$$

In the continuation of this work the added mass due to the injected fuel will be neglected in comparison with $m_{g}$.

\subsubsection{Heat Release}

A combined heat and power system produces heat through the water cooling system $Q_{g w}(\theta)$ and on the flues gas, Equation (18) hereafter:

$$
Q_{e x h}=\int_{E V O}^{E V C} \frac{d m_{e x h}(\theta)}{d \theta} \cdot c_{p}\left(T_{g}(\theta)\right) \cdot\left(T_{g}(\theta)-T_{a t m}\right) \cdot d \theta
$$

The heat release through oil lubricant is not considered here, but it becomes important for high power engine.

\subsubsection{Exergy Analysis}

The heat release on water cooling system and the heat release to environment by the flue gas represent the heat energy released by the system. But the first law of thermodynamics is insufficient to account for the real quality of the powerheat plants; because the electricity is put on the same value level than heat.

The exergy contents of the heat are defined according to Equations (19-21):

- exergy of water cooling system:

$$
\left(1-\frac{T_{0}}{T_{r e e_{Q_{g w}}}}\right) \cdot Q_{g w}
$$

with $T_{r e f_{Q_{g}}}$ the characteristic temperature of the water cooling system;

- exergy of flue gas:

$$
\left(1-\frac{T_{0}}{T_{r e f_{Q x h}}}\right) \cdot Q_{e x h}
$$

with $T_{r e f_{Q_{e x h}}}$ the characteristic temperature of the flues gas (arithmetic averaging of the temperature during the exhaust phases);
- exergy of the fuel (natural gas here):

$$
\left(1-\frac{T_{0}}{T_{r e f_{Q_{c o m b}}}}\right) \cdot Q_{\text {comb }}
$$

with $T_{r e f_{Q_{c o m b}}}$ the adiabatic flame temperature of the natural gas.

\section{RESULTS AND DISCUSSION}

In this section, simulation results are presented. The equation system describing the engine $(E q .2,3,5)$ is solved with Runge Kutta 4th order algorithm. The results are obtained for a simulation using the following parameters, given in Table 1.

TABLE 1

Values of parameters

\begin{tabular}{l|c}
\hline Designation & Values \\
\hline Displacement volume & $0.5 \mathrm{~L}$ \\
\hline Stroke/Bore & 1 \\
\hline$r_{b m}$ & 0.275 \\
\hline Intake opens & $9^{\circ}$ before TDC \\
\hline Intake closes & $59^{\circ}$ after BDC \\
\hline Exhaust opens & $57^{\circ}$ before BDC \\
\hline Exhaust opens & $11^{\circ}$ after TDC \\
\hline Spark timing & $15^{\circ}$ before TDC \\
\hline Engine speed & $1500 \mathrm{rpm}$ \\
\hline Compression ratio & 11.3 \\
\hline Fuel air ratio & 0.8 \\
\hline
\end{tabular}

The area of the $P(V)$ diagram is the mechanical work for the single cylinder, see Figure 2. It agrees well with the experimental results obtained on a CHP gas engine [20].

The temperature versus crankshaft angle proposes the expected gas temperature evolution, Figure 3. The mixing phase during the valves crossing between fresh air and burned gas is also visible in the figure. This is generally not considered in the cited literature reported here.

The following figures show the gas mass evolution during one cycle.

In Figure 4 like in Figure 5 sonic blocking at the level of the exhaust valve is visible.

For different engine speed rotation, the different forms of energy are represented in Figure 6. The work produced by the engine but also the heat energy losses (in percentage).

It clearly appears that as the speed of the engine increases from $750 \mathrm{rpm}$ to $4750 \mathrm{rpm}$ the percentage of heat released with the flue gases evolves from $27 \%$ to $70 \%$. In the same time, the heat released on water cooling evolves from $31 \%$ to 


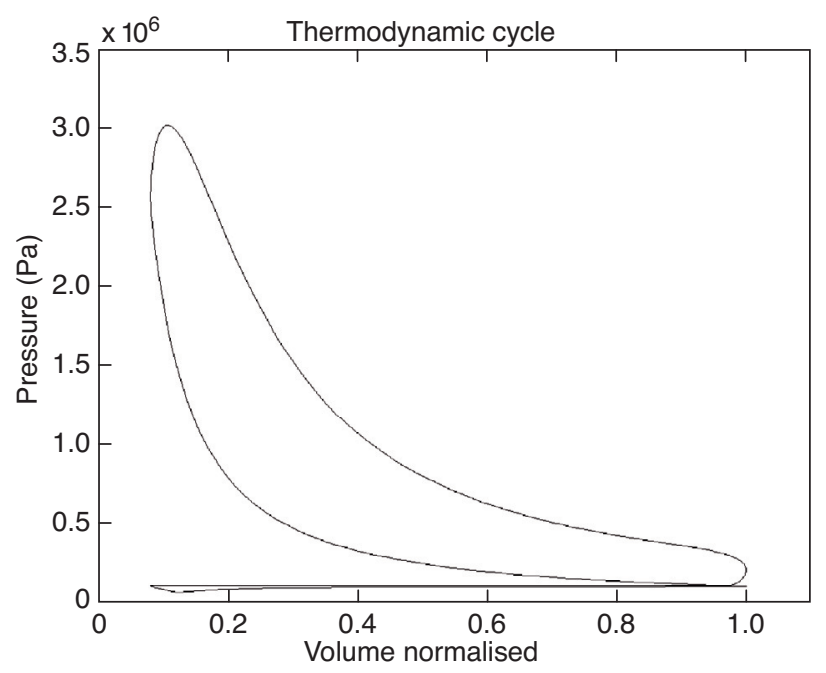

Figure 2

PV diagram.

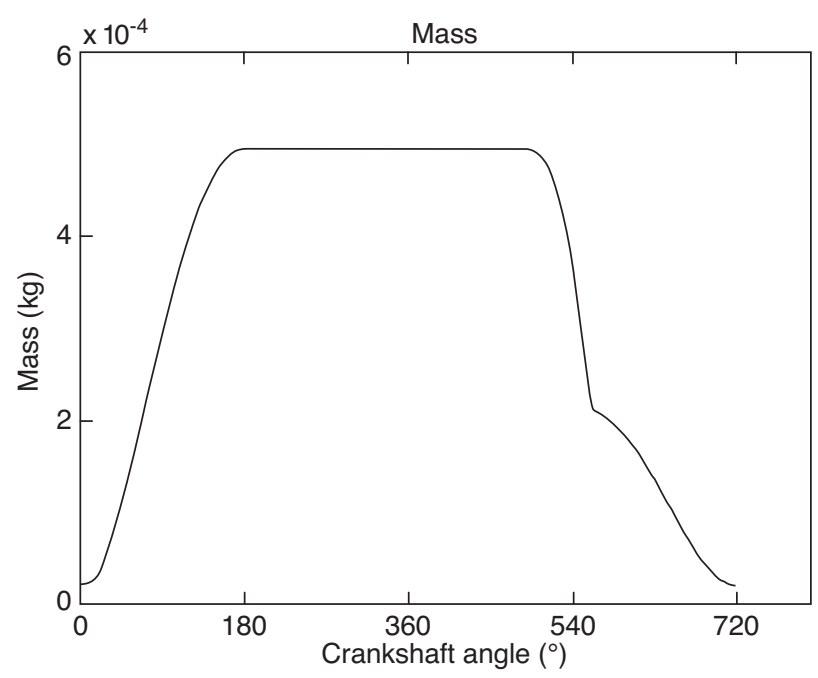

Figure 4

Mass variation in the cylinder during one cycle.

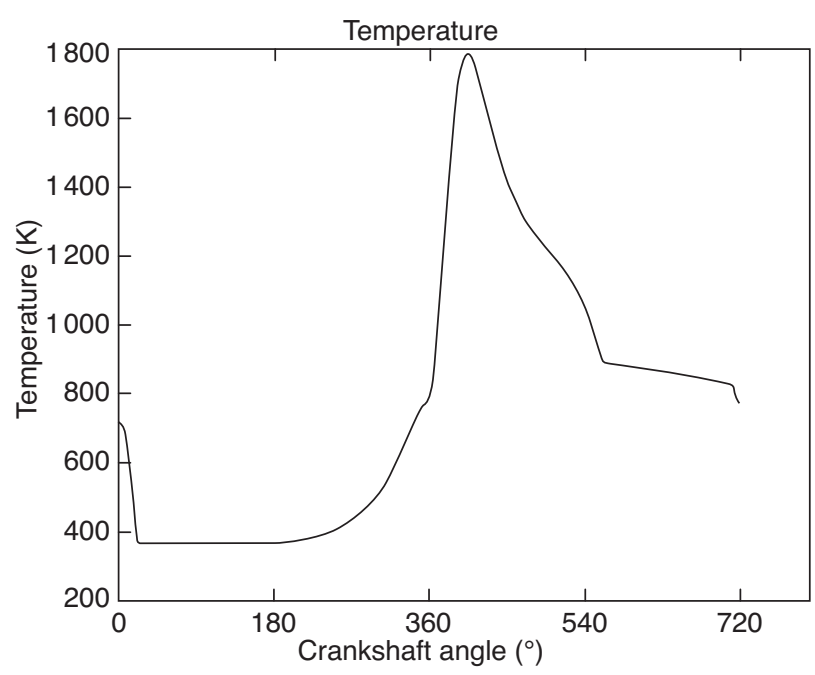

Figure 3

Temperature variation during one cycle.

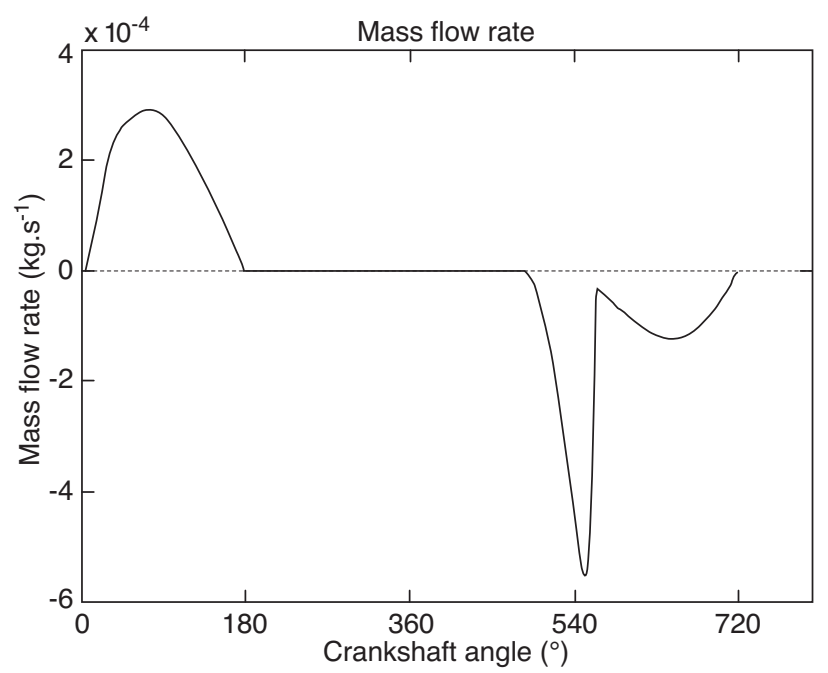

Figure 5

Mass flow rate variation during one cycle.
13\%. The two evolutions are in opposed directions. Therefore when the rotation speed of the engine increases, due to constancy of the available heat percentage at the combustion process, it appears a maximum of the work percentage associated to a minimum of the released heat, as can be seen on the $Q_{r e c}$ curve of Figure 6.

The curve $\left(Q_{\text {rec }}+W\right)$ shows that the other irreversibilities of the engine increase slightly in the same rotation speed variation range.

However this kind of analysis appears to the present authors insufficient, in order to have a good appraisal to valorize the rejected heat: the heat must be characterized by two variables. One is related to the existing heat quantity $Q$, and the second to the heat quality, through the temperature $T$. These two extensive variables are related through exergy definitions (relations 19 and 21).

Figure 7 gives a completely different appreciation of the heat release potential. The whole curve of water cooling exergy is under the one of flue gas exergy curve, and the two exergy curves percentages are near of $10 \%$ instead of $30 \%$ in energy. Then, the same decreasing tendency for water cooling curves or increasing tendency for flue gas heat rejected are registered. But using exergy analysis we see in Figure 7 that we don't recover the minimum of the total available heat 


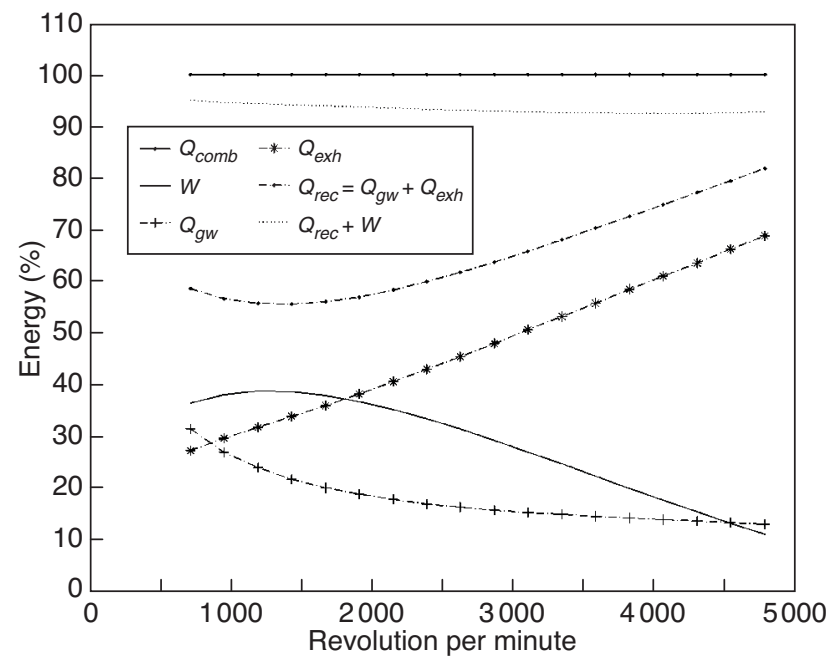

Figure 6

Energy repartition evolution with the engine rotation speed.

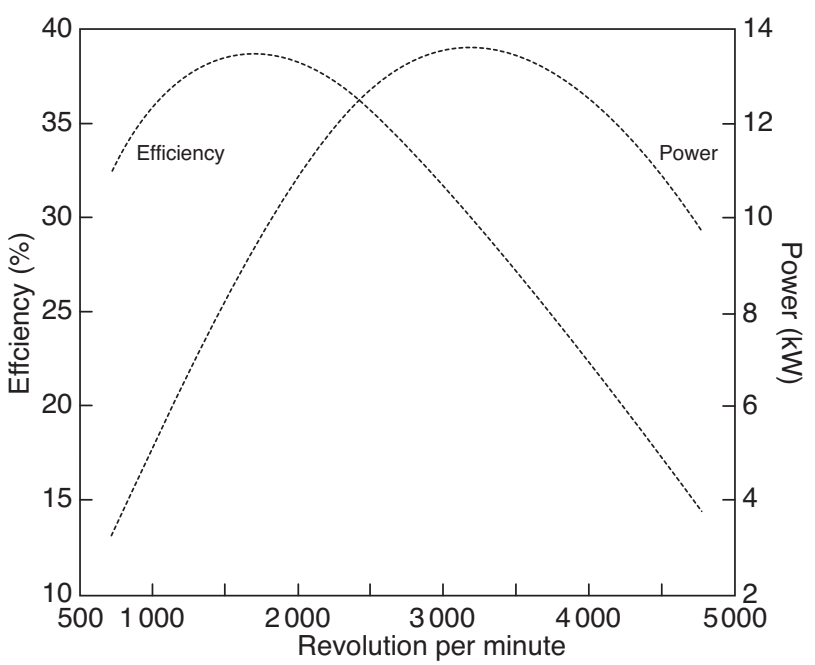

Figure 8

Power and efficiency versus the engine rotation speed.

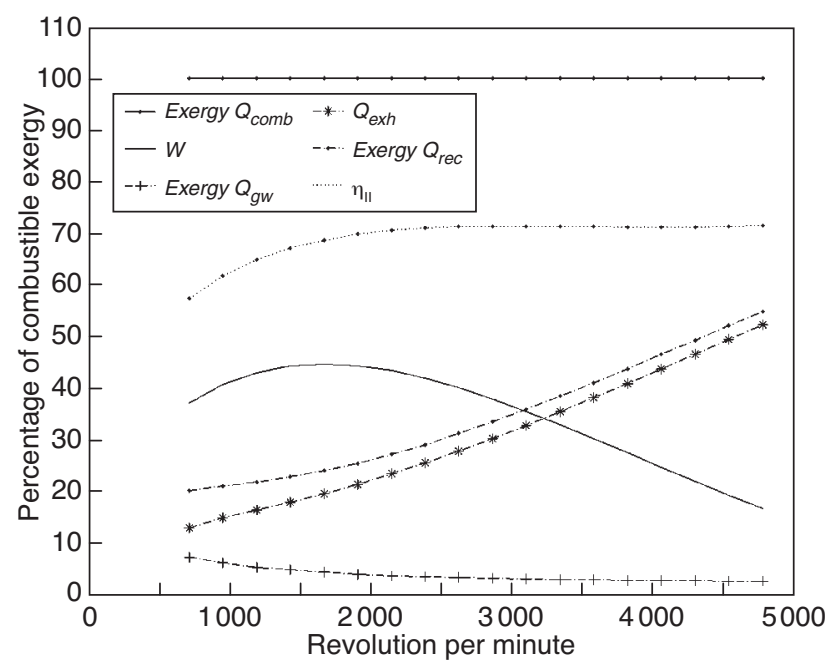

Figure 7

Exergy repartition.

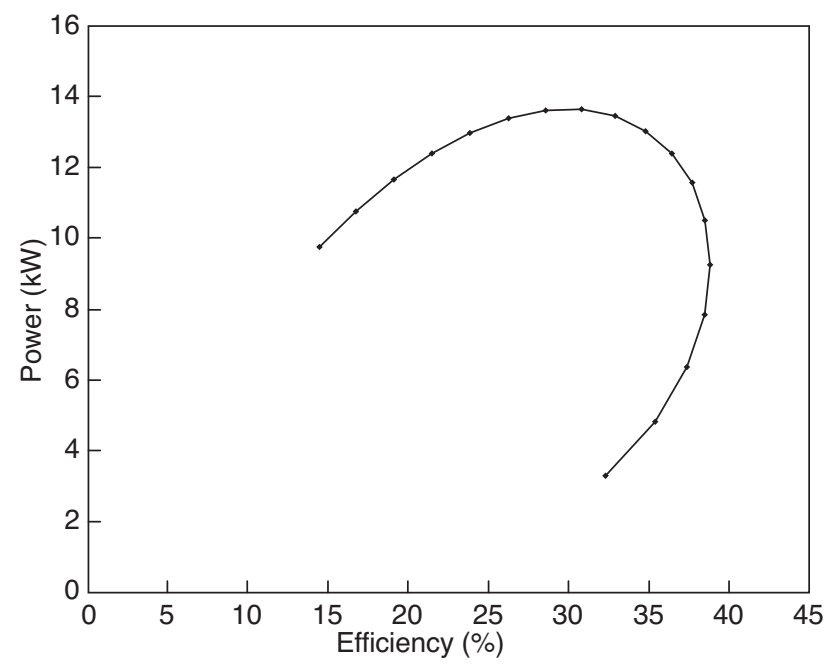

Figure 9

Power versus efficiency. rejected, as was the case for energy repartition (Fig. 6). This time the total available heat exergy is always increasing from $20 \%$ to approximately $55 \%$, the main part at high speed coming from flue gas.

So in order to valorize the rejected heat, the conclusion is to use cooling water for air conditioning purpose only, and to valorize the flue gas exergy to electricity production/ thermoelectricity, ORC - Organic Rankine Cycle possibly, or Stirling engine. Researches are under development in our group in this direction now [21].

Second law efficiency, $\eta_{\mathrm{II}}$, defined as the ratio of the useful exergy (Exergy of $Q_{r e c}+W$ ) on the combustion exergy
(Exergy combustion). Second law efficiency is near of $70 \%$ mainly in the speed interval of [2 500-5 000] rpm, less that the first law efficiency which is near of $95 \%$.

According to the proposed model traditional curves are also calculated, namely power and efficiency variation according to the engine rotation speed (see Fig. 8). But the combination of these two curves allows the creation of a third one which represents the power versus the efficiency (Fig. 9). The latter curve highlights two privilegied operating points for the engine: a mode of maximum efficiency and another one of maximum power for the same conditions as for Figure 7, (Tab. 1). 


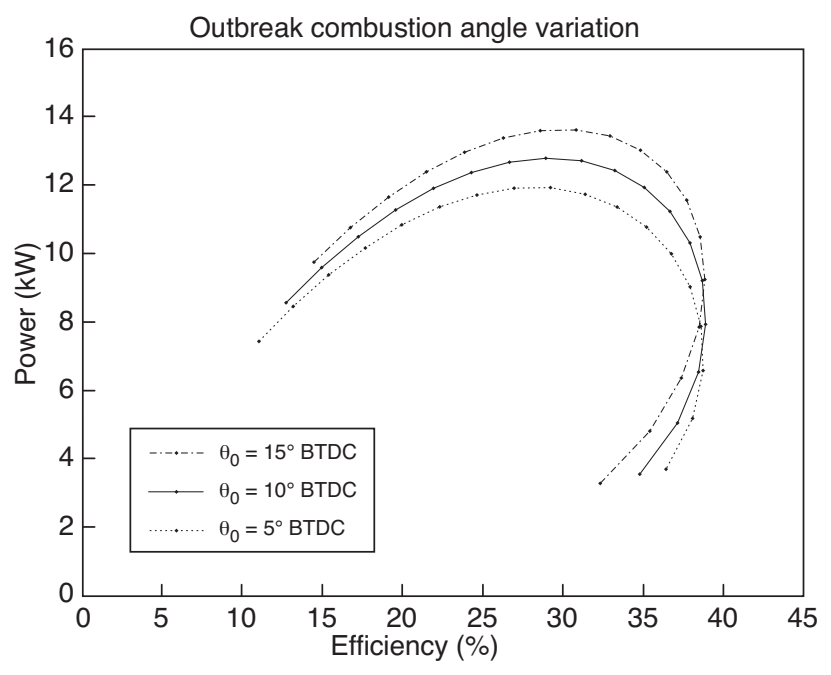

Figure 10

Influence of outbreak combustion.

This type of representation (Fig. 9) allows determining an optimal operating range of the engine between the two privilegied operating points, the maximum of efficiency and the maximum of power. For the studied engine the operating range is between 1500 and $3250 \mathrm{rpm}$. This corresponds to experimental results of the tested engine.

In Figure 10 the evolution of this curve is exposed for the variation of the crankshaft angle marking the outbreak of the combustion.

This parameter has a strong influence on the maximum power and less on the maximum efficiency, as it can be seen. The maximum of power increase is $10 \%$ for nearly similar engine rotation speed. This sensitivity analysis has been reported only for the parameter $\theta_{0}$ that seems to be the most influent. It could be interesting to complete this analysis for other parameters; this will be done in the near future and seems to have never been done in the past using Finite Time Thermodynamics models.

\section{CONCLUSION}

- The Finite Dimensions Thermodynamics proposed model allows recovering fundamental curves giving power versus engine efficiency and the corresponding rotation speed, but enlarged in comparison with preceding results. Il also allows sensitivity analysis to more parameters.

- Regarding the preceding results, the proposed one zone model takes account of:

- mass flow in admission and exhaust part of the system;

- combustion model using a simple Wiebe law;

- effect of thermal losses through cylinder wall, all along the transformations that the gas undergoes in the cylinder.
This is the first attempt to our knowledge in the corresponding cited literature, but with a supposed constant wall temperature.

The model is consistent with experimental results obtained on a gas engine.

- The proposed model allows an easy sensitivity analysis to parameters. An example has been given regarding the outbreak combustion angle variation. Other parameters influence will be reported in the near future.

- Exergy versus energy analysis has been performed for the studied engine. It results that in the experimental conditions only $70 \%$ of the combustion exergy is usable over the rotation speed range of [2 500-5 000] rpm, and that the main part of this exergy comes from flue gas when growing from $25 \%$ at $2500 \mathrm{rpm}$ to $50 \%$ at $5000 \mathrm{rpm}$.

- This allows more specific studies with thermoelectric converters, Organic Rankine Cycles (ORC) or Stirling engine in cascade with the Otto Engine. These complementary studies are under development in our group, and in collaboration with other universities [21].

\section{REFERENCES}

1 Chen L., Ge Y., Sun F. (2008) Unified Thermodynamic Description and Optimization for a Class of Irreversible Reciprocating Heat Engine Cycles, Proc. IMechE Part D: J. Automobile Engineering 222, D8, 1489-1500.

2 Hoffman K.H., Watowich S.J., Berry R.S. (1985) Optimal Paths for Thermodynamic Systems: the Ideal Diesel Cycle, J. Appl. Phys. 58, 6, 2125-2134.

3 Angulo-Brown F., Fernandez-Betanzos J., Diaz-Pico C.A. (1994), Compression Ratio of an Optimized Otto-Cycle Model, Eur. J. Phys. 15, 1, 38-42.

4 Ge Y., Chen L., Sun F. (2008) Finite Time Thermodynamics Modeling and Analysis for an Irreversible Otto Cycle, Appl. Energy 85, 7, 618-624.

5 Ebrahimi R. (2010) Effects of Variable Specific Heat Ratio on Performance of an Endoreversible Otto Cycle, Acta Phys. Pol. A 177, 6, 887-891.

6 Chen L., Lin J., Lou J., Sun F., Wu C. (2002) Friction Effect on the Characteristic Performances of Diesel Engines, Int. J. Energy Res. 26, 11, 965-971.

7 Ebrahimi R. (2009) Performance of an Irreversible Diesel Cycle under Variable Stroke Length and Compression Ratio, J. Am. Sci. 5, 7, 58-64.

8 Chen L., Sun F., Wu C. (2004) Optimal Performance of an Irreversible Dual Cycle, Appl. Energy 79, 1, 3-14.

9 Ghatak A., Chakraborty S. (2007) Effect of External Irreversibilities and Variable Thermal Properties of Working Fluid on Thermal Performance of a Dual Internal Combustion Engine Cycle, J. Mech. Energy 58, 1, 1-12.

10 Ge Y., Chen L., Sun F. (2009) Finite Time Thermodynamics Modeling and Analysis for an Irreversible Dual Cycle, Math. Comput. Model. 50, 1-2, 101-108.

11 Angulo-Brown F., Navarette-Gonzalez T.D., Rocha-Martinez J.A. (1999) An Irreversible Otto Cycle Including Chemical Reactions, in Recents Advances in Finite Time Thermodynamics, Wu C.et al. (eds), Nova Science Palo, pp. 491-505. 
12 Rocha-Martinez J.A., Navarette-Gonzalez T.D., Pava-Miller C.G. et al. (2006) A Simplified Irreversible Otto Engine Model with Fluctuations in the Combustion Heat, Int. J. Ambient Energy 27, 4, 181-192.

13 Chen L., Wu C., Sun F., Wu C. (1998) Heat-Transfer Effects on the Net Work-Output and Efficiency Characteristics for an Air Standard Otto Cycle, Energ. Convers. Manage. 39, 7, 643-648.

14 Merabet A., Feidt M., Bouchoucha A. (2002) Effect of Heat Transfer on the Performance of an Atmospheric Spark Ignition Engine Operating Upon a Dual Cycle, Termotehnica 2, 43-46.

15 Hohenberg G. (1979) Advanced Approaches for Heat Transfers Calculation, SAE Technical paper 790825.

16 Heywood J.B. (1988) Internal Combustion Engines Fundamentals, Mc Graw Hill, ISBN 0-07-100499-8.

17 Guibert P. (2005) Modelling of Direct Cycle; Spark Ignition Engine, Techniques de l'Ingénieur, BM 2511.
18 Tazerout M., Lecorre O., Stouffs P. (1999) Compression Ratio and TDC Calibrations using Temperature Entropy Diagram, $S A E$ Technical paper 1999-01-3509.

19 Arquès P. (2004) La combustion : Inflammation, Combustion, Pollution, Applications, Ellipses, Paris, 304 p., ISBN 2-72982037-X.

20 Descieux D. (2007) Modelling and Exergetic Comparison of Cogeneration Systems, PhD Thesis, University of Nancy, France.

21 Mc Govern et al. (2010) Validation of a Simulation Model for a Combined Otto and Stirling Cycle Power Plant, ASME 4th International Conference on Energy Sustainability, ES 201090220, Phoenix, Arizona, USA.

Final manuscript received in July 2011 Published online in September 2011 